\title{
CONGENITAL OBLITERATION OF THE BILE DUCTS
}

\author{
IN A GHILD WHO LIVED FOR THREE YEARS AND THREE MONTHS
}

BY

\author{
CONSTANCE FINLAYSON, M.B., B.S., \\ Adelaide.
}

The condition is comparatively rare although over 175 reports of cases have been recorded and reviewed by J. Thomson ${ }^{1}$, Rolleston and Hayne ${ }^{2}$, Parsons and Hickmann ${ }^{3}$, Wyard ${ }^{4}$, Hill $^{5}$, and others. The degree of severity of the lesions varies greatly. There may be blocking of patent ducts by inspissated bile giving rise to jaundice. Cases of this nature operated on by Ladd $^{6}$ cannot come into the category of obliteration of the bile ducts. In most instances death takes place in the first few months of life. Thomson says, "If these children are not carried off by haemorrhage or some other such cause during the first week or two they generally live from three to eight months.' This case is reported because the child lived for over three years.

\section{Case report}

H. L., female, was born at Peterborough, South Australia, weighing $4 \frac{1}{2} \mathrm{lbs}$. The mother, aged 32 years, was a primipara. She appeared to be quite healthy and there was no history of miscarriages. Five weeks before full term there was bleeding from the uterus and a lateral placenta praevia was suspected but not felt. After twenty-four hours of moderate bleeding labour began spontaneously and after six hours the infant was born. The puerperium was normal except that the breast milk failed owing to the inability of the infant to suck.

During the first week the baby showed signs of slight jaundice, the colour deepening after the third week. She was at first fed on breast milk supplemented by a cow's milk and water mixture, then on cow's milk and water only, and as the gain in weight did not average more than three ounces a week various artificial foods were tried without avail. On April 10,1933 , the probable diagnosis was made of congenital obliteration of the bile ducts. At this time the jaundice was of a yellow green colour. The stools showed no bile pigment, the urine was deeply coloured. The weight was $8 \mathrm{lb} .14 \mathrm{oz}$. The Wassermann reaction was negative.

The child was first seen on September 26, 1933, at the age of ten months, and weighing $12 \mathrm{lb}$. $4 \mathrm{oz}$. The skin and sclerotics were a deep yellowish-green colour, the stools were pale and had been so from birth. The urine contained bile but otherwise showed no abnormality. The liver edge could be felt a finger's breadth below the right costal margin; the spleen was palpable. Signs of rickets were obvious, there was beading of the ribs and bowing of the long bones, especially the tibiae. Radiological examination of the bones showed the signs characteristic of the disease. The diet up to this period had consisted of a skimmed dried milk and baked flour. Radiostoleum was given in the first week of October, 1933, and the dose gradually increased from 5 minims to 30 minims daily. This was 
continued until May, 1935, when the amount was reduced to 10 minims daily. The diet was increased to approximately that of a normal baby of ten months old except that fats, which tended to cause vomiting, were not given. The weight remained stationary for three weeks.

Laparotomy was suggested in the hope that the condition might prove amenable to surgical treatment. On October 18, 1933, under ether anaesthesia Dr. A. M. Cudmore opened the abdomen and explored the region of the gall bladder and bile ducts which were found in their usual anatomical position. The gall bladder was small, white in colour, with thick walls and appeared to be empty. No fluid, either bile or mucus, could be drawn into a hypodermic necdle and syringe. The ducts were white in colour and felt like hard cords. It was obvious that no operative procedure could remedy the condition. Recovery from the operation was uneventful except for a fairly severe haemorrhage from the wound on the second day. The patient remained in hospital until December 8, 1933. Her diet at this time consisted of thirty ounces of skimmed milk, cereals, banana, scraped apple, spinach, brains, orange juice and 30 minims of radiostoleum daily. Her weight was now $13 \mathrm{lb} .4 \mathrm{oz}$.

The child was next seen on June 5, 1934. Jaundice was now deep green, the urine contained bile, the stools were clay-coloured. She now weighed $16 \mathrm{lb} .3 \mathrm{oz}$. The liver and spleen had increased in size. The signs of rickets were less. Pruritus was now a distressing symptom and had been present since January, 1934. She was continually scratching first one part of her body and then another, including her head. Scratch marks showed signs of bleeding especially behind the ears. There were raised circular areas in the skin slightly paler in colour than the body generally, arranged in clusters in regions that were most subject to scratching. These nodules appeared in March, 1934, two months after the pruritus began. In January, 1935, dextrose was suggested as a possible relief from the irritation. This was given in increasing amounts, beginning with three heaped teaspoonsful of the powder a day, until eight teaspoonsful were given as a routine in addition to the ordinary sugar in her food.

The patient was again seen in April, 1935. Her condition was as before except that the liver and spleen had increased in size and since taking the dextrose pruritus was much less troublesome. There were no obvious signs of rickets. During this visit to town she had a respiratory infection which lasted a few days, the temperature reaching a maximum of $102^{\circ} \mathrm{F}$.

Writing in May, 1935, the mother states 'Since taking the dextrose in large quantities the irritation is wonderfully improved. The nodules in the skin seem very much flatter and quite a number have disappeared. I think I can correctly say that no fresh ones have appeared . . . Baby sleeps wonderfully well and is happy, the dextrose has made a wonderful difference to her night's rest. She walks quite well.'

The child was seen on February 25, 1936, aged three years and three months and weighing $22 \frac{3}{4} \mathrm{lb}$. with a height of $33 \frac{1}{2}$ inches. The jaundice was now of a blackish green hue. The liver was greatly enlarged, the lower edge being felt a hand's breadth below the right costal margin on a level with the umbilicus. The spleen was palpable as an elongated hard mass filling the left half of the abdominal cavity with its lower pole in the left iliac fossa. The teeth were badly decayed, the upper incisors had broken off level with the gum margin. The cutaneous nodules had disappeared except for a few flattened ones in the groins, axillae and in the bend of the elbows. No pruritus was present; she walked, talked and seemed happy (fig. 1). The haemoglobin was 45 per cent. (Sahli).

On March 2, 1936, the child became listless, refused food and appeared to have a slightly sore throat. Respiration was rapid and the temperature $104.8^{\circ}$ F. There were no abnormal signs in the chest. Next day she was 
drowsy and cried out at intervals. The abdomen became distended, the urine contained bile and pus cells were present microscopically. There was no reduction of Fehling's solution. The right eyelid and periorbital region became swollen owing to a subcutaneous haemorrhage.

On March 5 there was slight haemorrhage from the mucous membrane of the mouth. The child's condition became rapidly worse and death took place at midday.

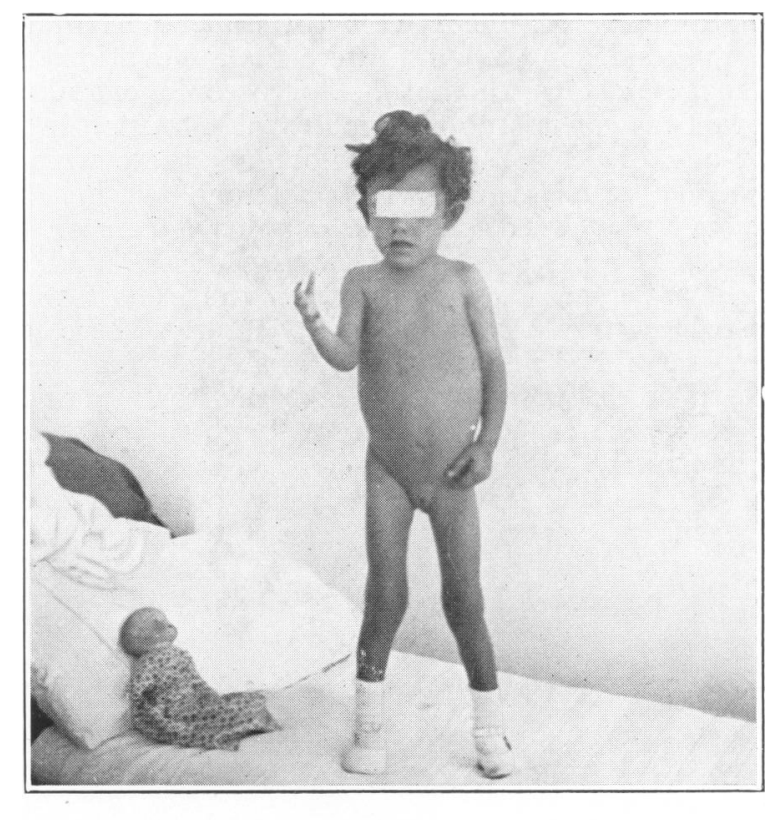

FIG. 1.

I am indebted to Dr. E. McLaughlin for the following report on a blood film:-

The erythrocytes show anisocytosis, some pallor, poikilocytosis and polychromatophilia. No nucleated forms seen. A very occasional myelocyte seen, otherwise there appears to be no very definite disturbance of the leucocytes. Abundant platelets present. The anaemia is of the hypochromic type.

Post-mortem findings. Professor J. B. Cleland kindly supplied the following notes:-

The body was deeply jaundiced with very little subcutaneous fat and no excess of fluid in the peritoneal cavity. There were a few adhesions in the region of the gall bladder. The gall bladder was small, $3 \mathrm{~cm} . \times 1 \mathrm{~cm}$. in size. Its contents were bile-stained. From the neck of the gall bladder a duct was pervious and bile-stained for half an inch, after which it was represented by an apparently impervious cord the size of thick catgut, extending straight downwards towards the ampulla of Vater and not showing any branches or connexion representing a junction with hepatic ducts. A probe could with difficulty be inserted into the ampulla of Vater from the lumen of the duodenum. The liver was tough and its substance very firm with a smooth capsule and was mottled olive-green in colour. The glands in the hilum of the liver were not enlarged although the mesenteric glands seemed rather red and slightly bigger than normal. The pancreas seemed normal. The spleen, which 
weighed $18 \frac{1}{2}$ ounces, was very large and extended to the iliac fossa; it was fairly firm, dark red in colour, and the Malpighian bodies were not recognizable. In the left kidney were groups of small abscesses with surrounding congestion at the upper pole, extending nearly to the pelvis. The right kidney showed two or three small white abscesses surrounded by red rings. Both kidneys were deeply jaundiced. The suprarenal glands were dark in colour and seemed to lack lipoid. There were numerous haemorrhages in the lungs with deep bile staining. In the skin on the upper part of the thigh and the abdominal side of the groin were little elevations about $1 \mathrm{~mm}$. in size, suggesting xanthomata. Microscopic examination of the liver showed a considerable amount of fibrosis, in some places unilobular and in other places intralobular; there were a number of lymphocytes in parts; there were occasional clumps of inspissated bile between the liver cells but no obvious distension of bile ducts. In the spleen the pulp was filled with red cells and an occasional plasma cell was seen. In the pancreas the islands were very large and often there were several close together. There were abscess cavities in the kidneys with cloudy swelling. Sections of a lymph gland showed prominence of the reticulo-endothelium and the presence of old blood pigment. The lung showed some alveoli packed with red cells and in others a grandular exudate. Sections of the elevation of the skin showed a few foamy cells beneath the epithelium. Staphylococcus aureus was grown from the kidney.

Dr. W. R. Morris, of Peterborough, kindly supplied the notes on the antenatal and early postnatal history.

\section{Summary}

This case is reported for the following reasons:-

1. The duration of life. As this condition is incompatible with life it is surprising that this child reached the age of three years and three months. The majority of cases reported in the literature have died before the eighth month. Patients who have lived longer than the one now reported have been proved to have had partial obstruction of the common duct with intermittent jaundice.

2. The absorption of vitamin D. It would seem that vitamin D present in radiostoleum is capable of being absorbed in the absence of bile in the intestine, as shown by the cure of rickets. One recorded case showed that the administration of cod-liver oil failed to arrest the development of rickets.

3. Relief of pruritus. This distressing symptom was relieved by giving eight teaspoonsful of dextrose daily in addition to the usual sugar and starch of the diet.

\section{REFERENCES}

1. Thompson, J., Edin. Med. J., Edinburgh, 1901, XXXVII, 606; System of Medicine, Allbutt \& Rolleston, London, IV, 103.

2. Rolleston, H., \& Hayne, L. B., Brit. Med. J., London, 1901, i, 758; Rolleston, H., Practitioner, London, 1920,

3. Parsons, L. G., \& Hickmann, E. M., Amer. J. Dis. Child., Chicago, 1926, XXXI, 461.

4. Wyard, S., Lancet, London, 1914, ii, 495.

5. Hill, N. H., ibid., 1927, ii, 654 .

6. Ladd, W. E., J. Amer. Med. Ass. Chicago, 1928, XCI, 1082. 